\title{
Manufacturing Planning and Execution Objects Foundation Interfaces
}

Shaw C. Feng

U.S. DEPARTMENT OF COMMERCE Technology Administration

Manufacturing Systems Integration Division Manufacturing Engineering Laboratory

National Institute of Standards

and Technology

Gaithersburg, MD 20899-0001

QC

100

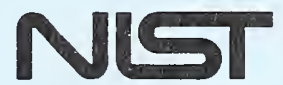

.056

N0.6232 



\title{
Manufacturing Planning and Execution Objects Foundation Interfaces
}

\author{
Shaw C. Feng
}

U.S. DEPARTMENT OF COMMERCE Technology Administration Manufacturing Systems Integration Division Manufacturing Engineering Laboratory National Institute of Standards and Technology

Gaithersburg, MD 20899-0001

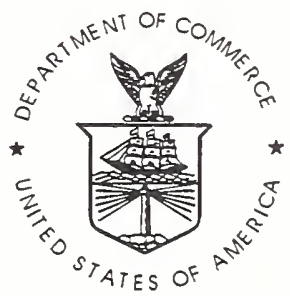

U.S. DEPARTMENT OF COMMERCE William M. Daley, Secretary

TECHNOLOGY ADMINISTRATION

Gary R. Bachula, Acting Under Secretary for Technology

NATIONAL INSTITUTE OF STANDARDS

AND TECHNOLOGY

Raymond G. Kammer, Director 



\section{CONTENTS}

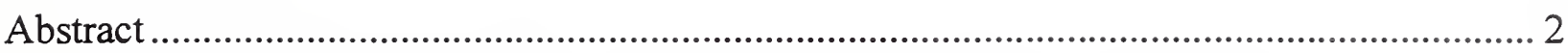

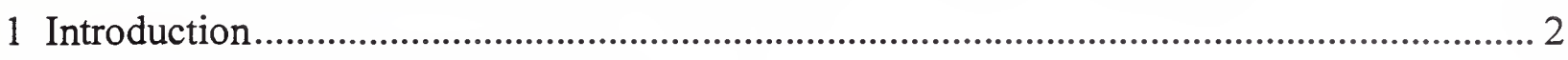

2 Manufacturing Execution System........................................................................................ 3

3 Manufacturing Planning and Execution Technology Integration Status ............................... 3

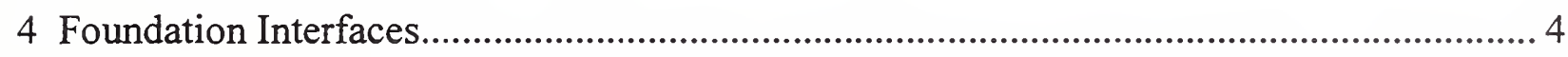

4.1 Manufacturing Execution Activity Model ...................................................................... 5

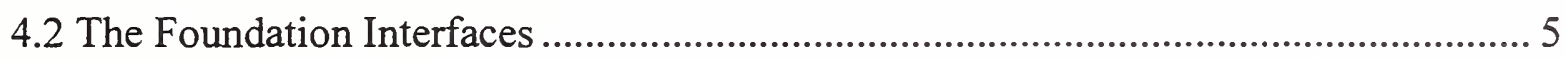

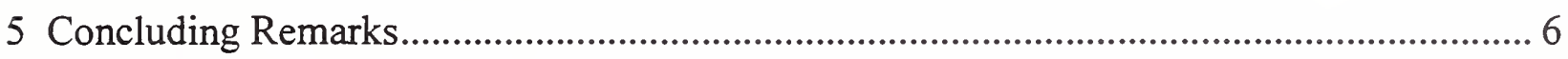

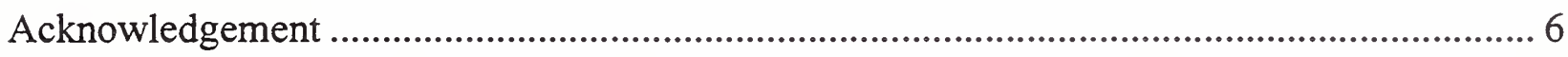

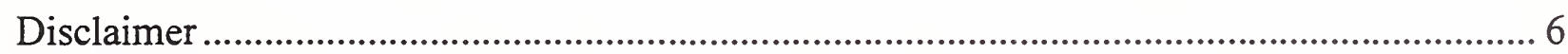

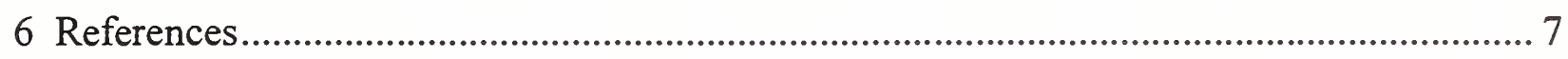

Appendix A. Design, Planning, Execution, and Control Activity Model................................... 9

A.1 Activity Model Graphical Representation ............................................................ 9

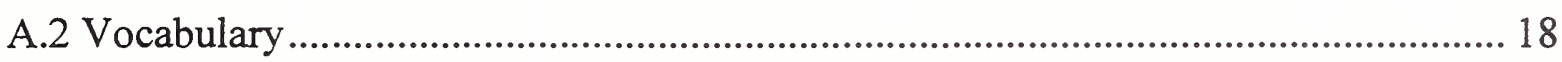

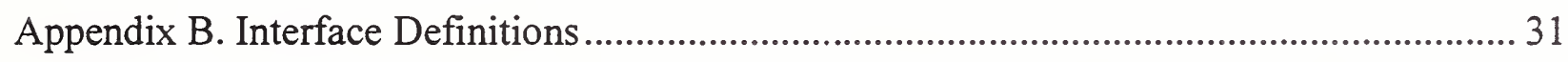




\begin{abstract}
Process planning and manufacturing execution systems provide two major functions in a product development cycle. Industries require the systems that support these two functions to be able to integrate with other related manufacturing systems, such as design, resource planning, production scheduling, and equipment control. However, there are information barriers to the integration of commercial systems in these areas. This paper presents an activity model for manufacturing execution and a set of foundation interfaces, identified in an object model, that have been developed to cope with the problem. The interfaces are intended to be a base from which they evolve as the new technology and industrial practices emerge.
\end{abstract}

\title{
1 Introduction
}

The integration of a manufacturing execution system (MES) [1] with related manufacturing applications, such as computer aided design (CAD), computer aided process planning (CAPP), and computer aided manufacturing (CAM), scheduling, enterprise resource planning (ERP), and equipment control systems, is a relatively new practice. Many industries currently use MES for managing factory-floor information and activities to increase productivity and improve quality. Examples of factory-floor information and activities are resource allocation, dispatching production units, quality management, operation planning, detailed scheduling, labor management, product tracking, and keeping records of product genealogy. Since $C A D$, CAM, CAPP, ERP, control, and scheduling systems support linked sets of activities and information flow, it is beneficial to industrial users if these manufacturing software systems can exchange data and messages (function calls) with each other in a diverse computing environment. This means that MES has to be an integrated component of a manufacturing system.

A feasible way of meeting this industrial need is to develop a mechanism to allow software, on a variety of platforms, to exchange data and messages. One way to develop such a mechanism is to design a system of standard interfaces so that different software systems can "plug and play." It is possible to develop such a system of interfaces using available technology in software "gluing," also referred to as middleware. A set of foundation interfaces has been developed for manufacturing planning and execution to cope with the integration and interoperability problems. These interfaces are documented in this report.

To better understand MES and its relationship to other manufacturing activities, this document provides the following theoretical basis: a definition of MES, the context in which an MES performs, its functions, and fundamental interface objects of MES. In addition to this section that introduces the foundation interfaces for manufacturing process planning and execution software integration, Section 2 provides a definition of MES. Section 3 describes current methodology and technology for manufacturing software integration. Section 4 contains the interfaces and the context in which they are developed and used. Section 5 concludes the paper with a call for continued development of standard MES interfaces. 


\section{Manufacturing Execution System}

The primary goal of MES is to provide an information system that can be used for optimizing production activities in a manufacturing facility with the focus on quick response to changing conditions. Some subgoals of MES are as follows [2]:

(1) to improve communication inside a facility, e.g., part programs can be electronically downloaded from CAM systems to machine tools, production activities can be rescheduled to reflect unexpected machine down time or production priority changes,

(2) to improve communication capability between production and other activities in a manufacturing enterprise, such as product design, process planning, resource planning, supply chain management, service and sales, and equipment control,

(3) to monitor production in order to control operations within desired performance parameters,

(4) to provide up-to-the-minute communication between the facility and facility management, and

(5) to better manage production-related data, including resource data, performance data, process data, job scheduling data, equipment/device control programs, etc.

With the goal of MES, a definition can be given as follows:

MES is a system that consists of a set of integrated software and hardware components that provide functions for managing production activities from job order launch to finished products. Using current and accurate data, an MES initiates, guides, responds to, and reports on production activities as they occur. MES provides production activity information to other engineering and business activities in the enterprise and its supply chain via bidirectional communications.

This definition is derived from a definition given in the Manufacturing Execution Systems Association (MESA) International White Paper 6 [3]. In the paper, only major functions in MES are described.

\section{Manufacturing Planning and Execution Technology Integration Status}

Standard interfaces for MES are necessary to solve the integration problems in a heterogeneous environment. The standard interfaces usually evolve from a series of three stages. (A related study on different maturity levels of standard interfaces is described in [4].) In the first stage, developers of a software system develop the specification of proprietary, vendor-specific interfaces. They are different from one system to another. Users/integrators have to develop translators for exchanging data between any two different systems. Consequently, the integration cost to software users is usually high. To alleviate the problem of interface incompatibility, some users and vendors join a consortium to develop a common set of interfaces which is sharable among users and vendors. This set of common interfaces is a product in the second stage. Common interfaces usually lead to some integration cost reduction. However, different consortia may develop different sets of interfaces, which are 
often incompatible, for the same application domain. More users and vendors realize the needs of creating standard interfaces based on consensus on the international level. Thus, the final stage is interface standards development. Users, vendors, and researchers jointly develop interface standards, which are open, neutral, and internationally accepted.

Currently, commercially available manufacturing planning systems and execution systems operate on different hardware and software platforms, and these platforms are almost all incompatible with each other. To address this incompatibility, Object Management Group's (OMG) Common Object Broker Architecture specification (CORBA) [5] specifies a mechanism for software objects to interoperate on heterogeneous, distributed computing platforms. In CORBA, a portion of an application is either a client, which requests services, or a server, which provides certain services. Between a client and a server, a software broker matches requests made by a client to services provided by a server. Clients and servers can be written in a variety of programming languages and located on different platforms in a networked computing environment. To enable CORBA-based communications, the boundaries between client and server must be specified in CORBA's Interface Definition Language (IDL). Such a specification can then be used by a compiler, in a CORBA toolkit, to generate stub and skeleton code with which to glue applications together. These stubs and skeletons provide communication functions and an Application Programming Interface (API) accessible from a high level language such as $\mathrm{C}$ or $\mathrm{C}+\mathrm{H}$.

The Computer Integrated Manufacturing Applications Framework (CIMF), developed at Sematech [6], has adopted the basic strategy of managing manufacturing information using CORBA. The CIMF is designed for sharing planning and operational information on semiconductor wafer production among different control and planning software modules. The CIMF provides a set of basic entities and their relationships for semiconductor manufacturing shop-floor information management. In contrast, the content of interfaces described in this report enable general software interoperation in the mechanical product manufacturing domain.

\section{Foundation Interfaces}

Based on the CORBA methodology, a set of interfaces has been developed for the manufacturing planning and shop-floor execution information management for mechanical parts production. The goal of the interface design is to make the interfaces open, neutral, and extendable. The developed interfaces serve as a foundation on which more specific object interfaces can be derived and made interoperable using CORBA. Users could extend the model by specializing, overriding, and extending some of the interfaces. The interfaces in this report are in the first version. Modification and enhancement of them will take place in the future as the technology and practices evolve.

For the purpose of clarifying process planning taking place in CAPP systems and some planning/scheduling activities taking place in manufacturing execution systems, the boundary between process planning and detailed planning activities at the manufacturing execution level is given as follows. The specification process, which defines operations, their sequences, and the selection of manufacturing resources before any product is produced, is 
within the scope of process planning. Detailed operation planning and scheduling performed at the workstation level after the work order is issued or during the production, is within the scope of manufacturing execution.

\subsection{Manufacturing Execution Activity Model}

Based on the IDEF0 methodology and techniques [7], an activity model ${ }^{1}$ of product development has been developed in reference to a product realization model in [8]. The top level activity is Develop Products (A0). This activity is decomposed into a series of six subactivities: Engineer Product and Process (A1), Plan Enterprise Resources (A2), Acquire Resources (A3), Execute Manufacturing Orders (A4), Manage Sales and Services (A5), and Control Equipment and Process (A6). The subactivities A4 covers the manufacturing execution functions and is further decomposed to set the context for the development and use of the foundation interfaces. The decomposition of the activity Engineer Process, which is equivalent to process planning, is in the NISTIR 5808 [9]. However, A1, A2, A3, A5, and A6 are there to show their relations to A4. The Engineer Product in A1, A2, A3, A5, and A6 are out of the scope in the interfaces development. The vocabulary contains terms only found in A4 and its subactivities. In addition to NISTIR 5808, a detailed dimensional inspection process planning model for discrete part inspection in the product development cycle is in [10].

The activity model is documented using the IDEF0 diagrams and contained in Appendix A. The IDEF0 diagrams are in Appendix A.1, and the vocabulary is in Appendix A.2. Vocabulary includes three subsections: Terminology, Activity Definitions, and ICOM (Input, Control, Output, and Mechanism) Data Definitions. Common terms referred in activity and ICOM data definitions are defined in the terminology subsection. Definitions of all the activities (A-0, A0, A1, A2 ,.., A4423, A4424) are in the subsection of activity definitions. All the data elements in ICOM are defined in the subsection of ICOM definitions. The activity model is expected to be updated as the manufacturing technology and practices evolve.

\subsection{The Foundation Interfaces}

The interfaces are specified using CORBA IDL. Some of them are derived from the activities of process planning, manufacturing execution, and their subactivities, but there is not a oneto-one mapping. For example, the interface EquipmentTracking corresponds to activity A431 Track Resources, and the interface OperationSequencing corresponds to activity A411 Develop Production Activities. EquipmentTracking consists of one attribute of Equipment and two function calls track_equipment and report_status. This interface is used to define objects that are used for tracking a piece of machinery or a tool used in processing workpiece in a factory and reporting the status of the equipment.

\footnotetext{
${ }^{1}$ An activity is indicated by its name in a box. Input data, which are transformed by the activity to the output data, are on the left side of the box with arrows pointing to the box. Control data, which are used to regulate the internal process of the activity, are above the box with arrrows pointing to the box. Mechanism data, which support and enable the activity, are below the box with arrows pointing to the box. Output data are on the right side of the box with arrows pointing to the output data from the box.
} 
The interfaces are organized into two modules: the manufacturing process planning module and the manufacturing execution module. Each module contains data structures, interfaces, and type definitions. Appendix B contains the first version of these foundation interfaces.

\section{Concluding Remarks}

A set of foundation interfaces using CORBA/IDL for process planning and manufacturing execution software modules has been identified through object modeling. The interfaces will enable software modules in various hardware/software platforms and in different locations to exchange data and messages with each other. The object model in IDL will be updated to reflect emerging technologies and industrial practices in the future.

For future work, these interfaces will be taken to standard bodies, such as OMG, as an input from NIST through the NIST participation. Also, the interfaces developed here can be used for testing commercial implementations in an MES testbed, being established at NIST.

\section{Acknowledgement}

The development of the foundation interfaces is funded by the Technologies for the Integration of Manufacturing Applications (TIMA) focused program in the Advanced Technology Program (ATP). Thanks also go to Neil Christopher and Amy Knutilla for their suggestions on improving some technical and editorial aspects of this report.

\section{Disclaimer}

No approval or endorsement of any commercial products by the National Institute of Standards and Technology is intended or implied. Certain commercial software systems and interface specifications are identified in this report in order to facilitate understanding. Such identification does not imply recommendation or endorsement by the National Institute of Standards and Technology, nor does it imply that the software systems and interface specifications identified are necessarily the best available for the purpose. 


\section{References}

1. MESA International, "The Benefit of MES: A Report from the Field," White Paper 1, Manufacturing Execution Systems Association, Pittsburgh, PA 15215, 1997.

2. MESA International, "MES Functionalities \& MRP to MES Data Flow Possibilities," White Paper 2, Manufacturing Execution Systems Association, Pittsburgh, PA 15215, 1997.

3. MESA International, "MES Explained: A High Level Vision," White Paper 6, Manufacturing Execution Systems Association, Pittsburgh, PA, 1997.

4. Mowbray, T.J. and Zahavi, R. The Essential CORBA: Systems Integration Using Distributed Objects, John Wiley \& Sons, Inc. 1995.

5. The Common Object Request Broker: Architecture and Specification manual, version published by the Object Management Group, Inc., July 1996.

6. Computer Integrated Manufacturing (CIM) Framework Specification, version 1.5, Sematech, Austin, Texas, 1997.

7. Integrated Computer-Aided Manufacturing (ICAM) Architecture Part II, Volume IV Functional Modeling Manual (IDEF0), Material Laboratory, U.S. Air Force Wright Aeronautical Laboratories, June 1981.

8. "SIMA Reference Architecture Part 1: Activity Models," Edited by E. Barkmeyer, NISTIR 5939, National Institute of Standards and Technology, Gaithersburg, MD 20899, December 1996.

9. Feng, S., "A Machining Process Planning Activity Model for Systems Integration," NISTIR 5808, National Institute of Standards and Technology, Gaithersburg, Maryland, March 1996.

10. Feng, S., "A Dimensional Inspection Planning Activity Model," Journal of Engineering Design and Automation - special issue on Tolerance and Metrology for Precision Manufacturing, Vol. 2, No. 4, pp. 253-267, 1996.

11. Dorf, R.C. and Kusiak, A., Handbook of Design, Manufacturing and Automation, A Wiley-Interscience Publication, John Wiley \& Sons, Inc., 1994

12. Ullman, D.G., The Mechanical Design Process, published by McGraw-Hill, Inc., 1992.

13. Prasad, B., Concurrent Engineering Fundamentals, published by Prentice-Hall, Inc., 1996. 
14. Dixon, J.R. and Poli, C., Engineering Design and Design for Manufacturing, Field Stone Publishers, Conway, Massachusetts, 1995 
Appendix A. Design, Planning, Execution, and Control Activity Model

A.1 Activity Model Graphical Representation

Scope : Manufacturing Execution in Product Development

Purpose: Set the context for Manufacturing Planning and Execution Software Interfaces

Development

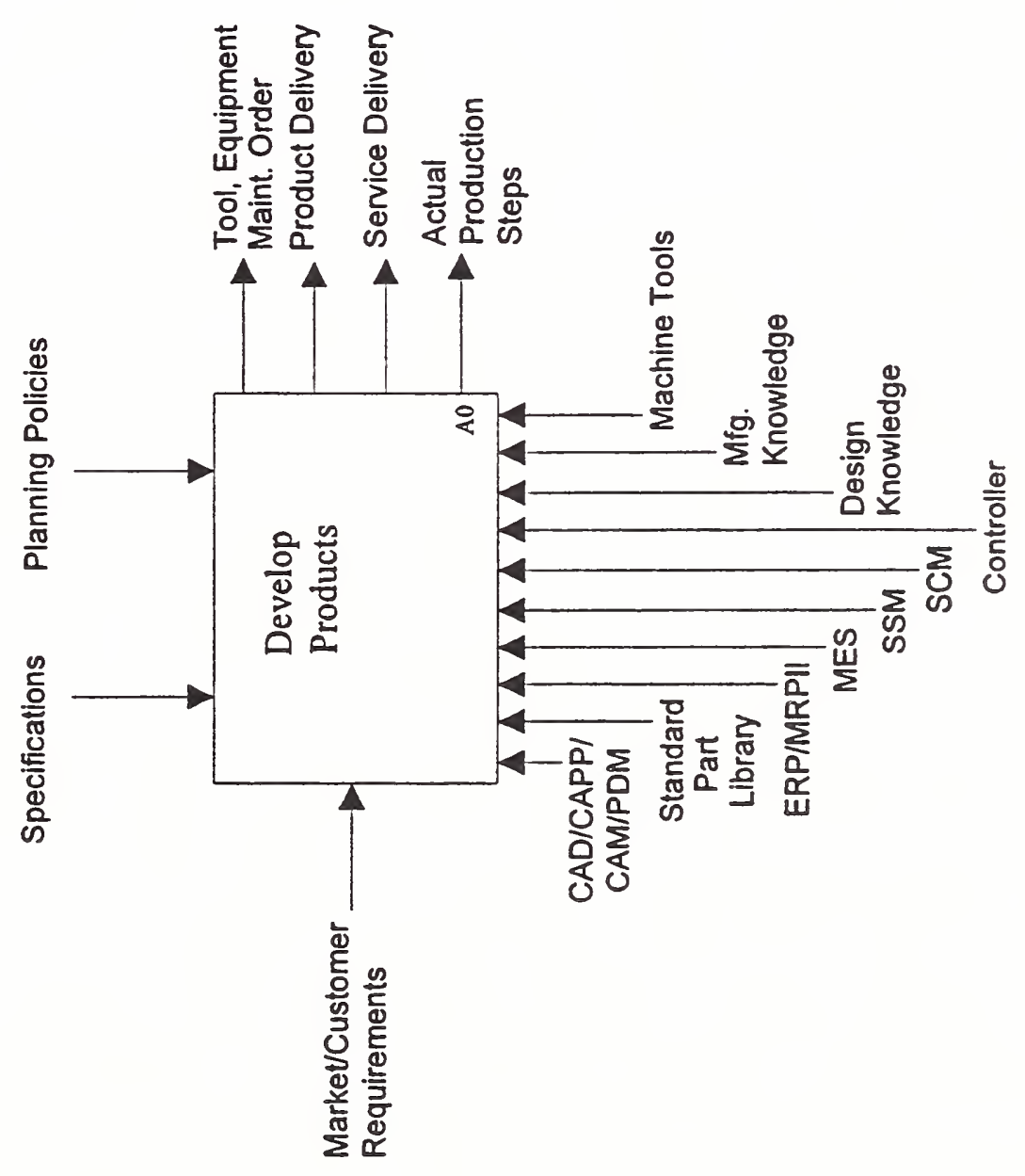

Activity A-0 


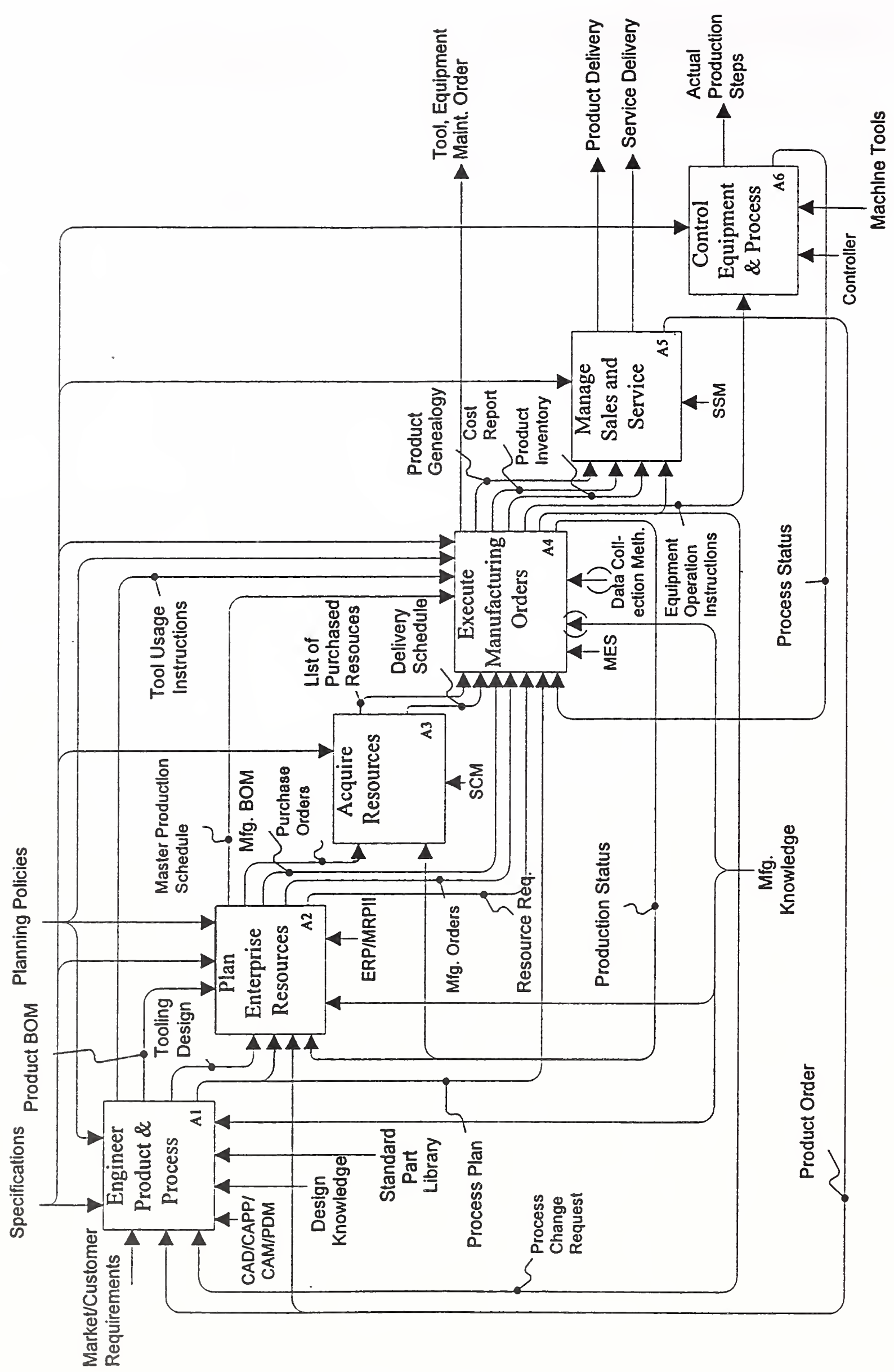

Activity A0 Develop Products 


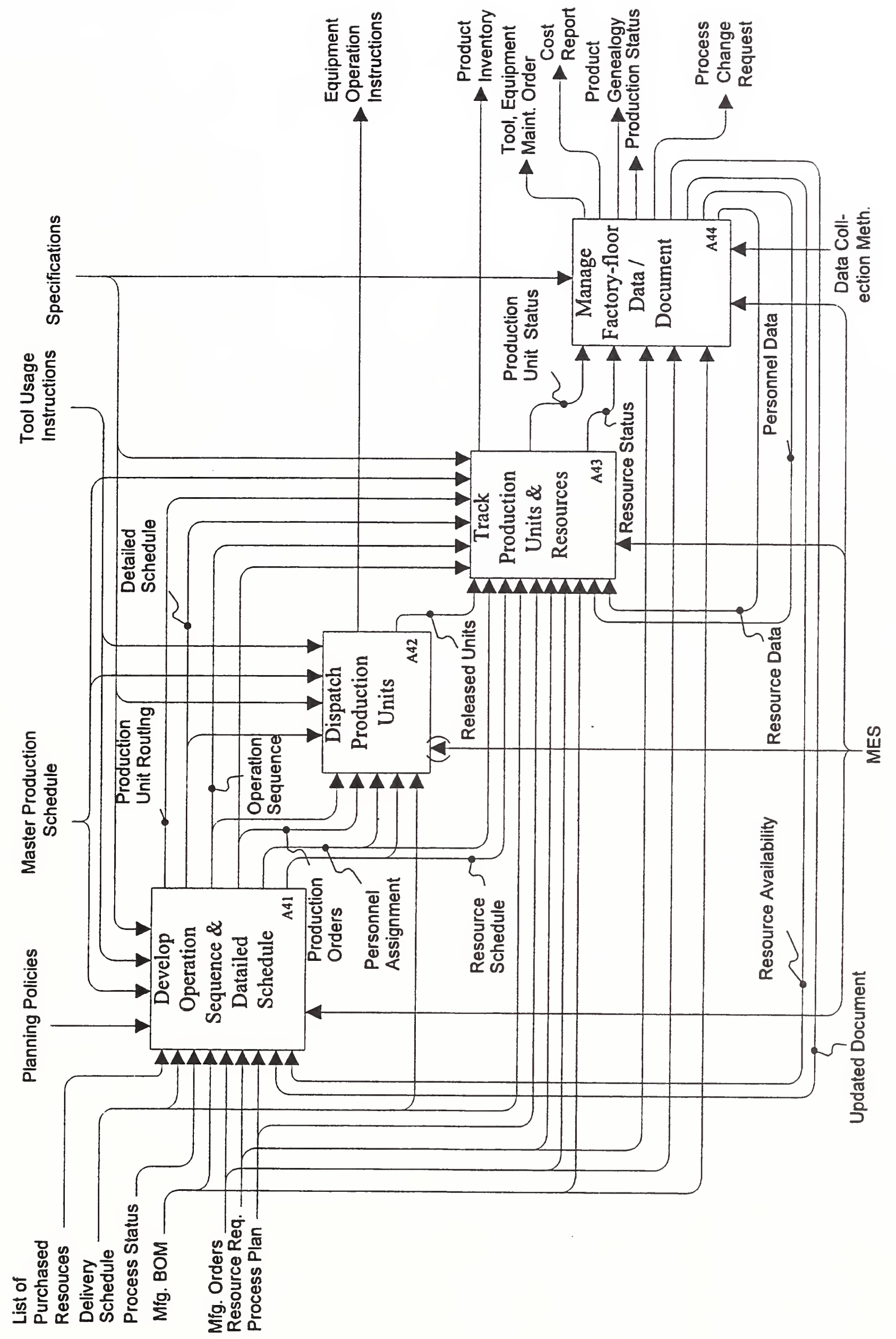

Activity A4 Execute Manufacturing Orders 


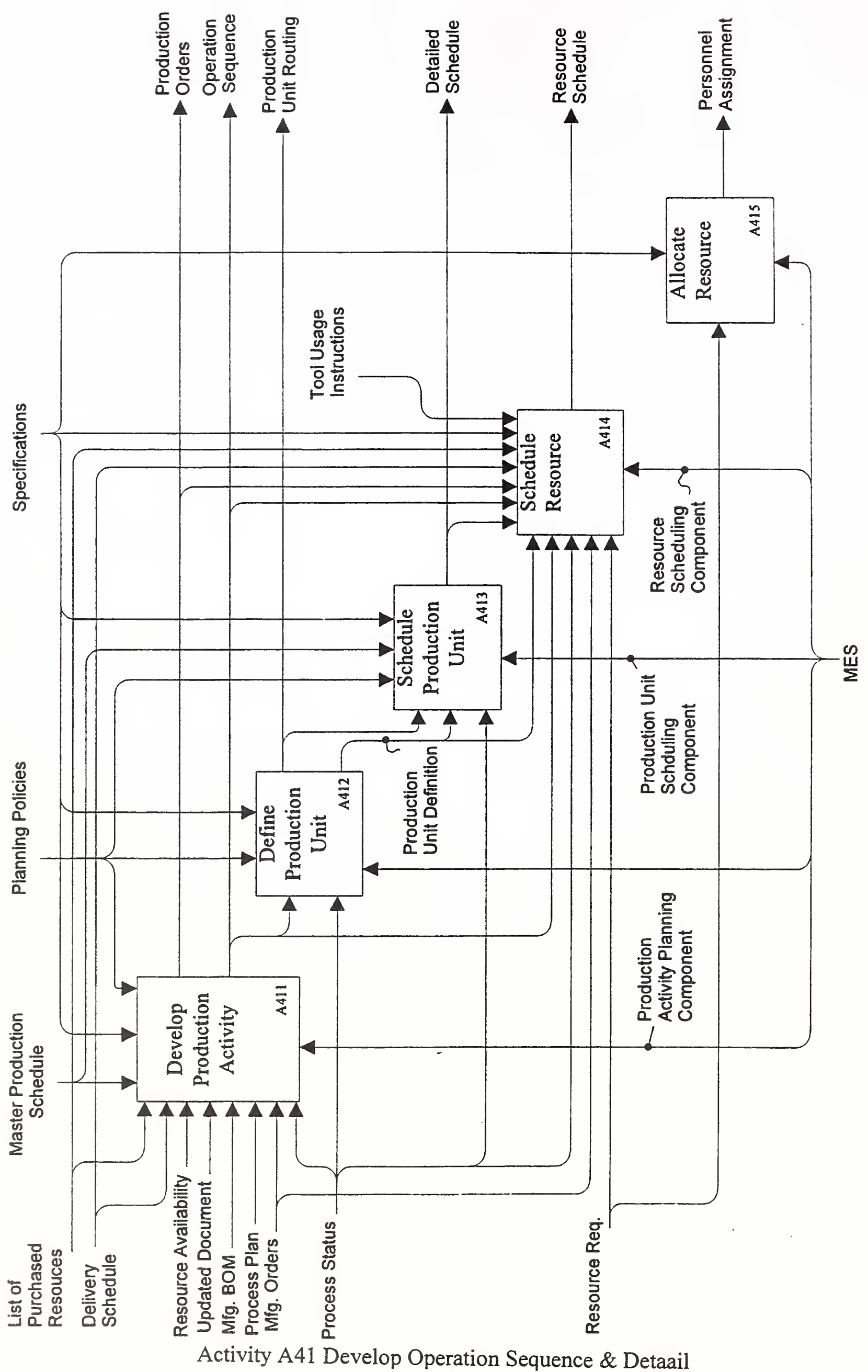




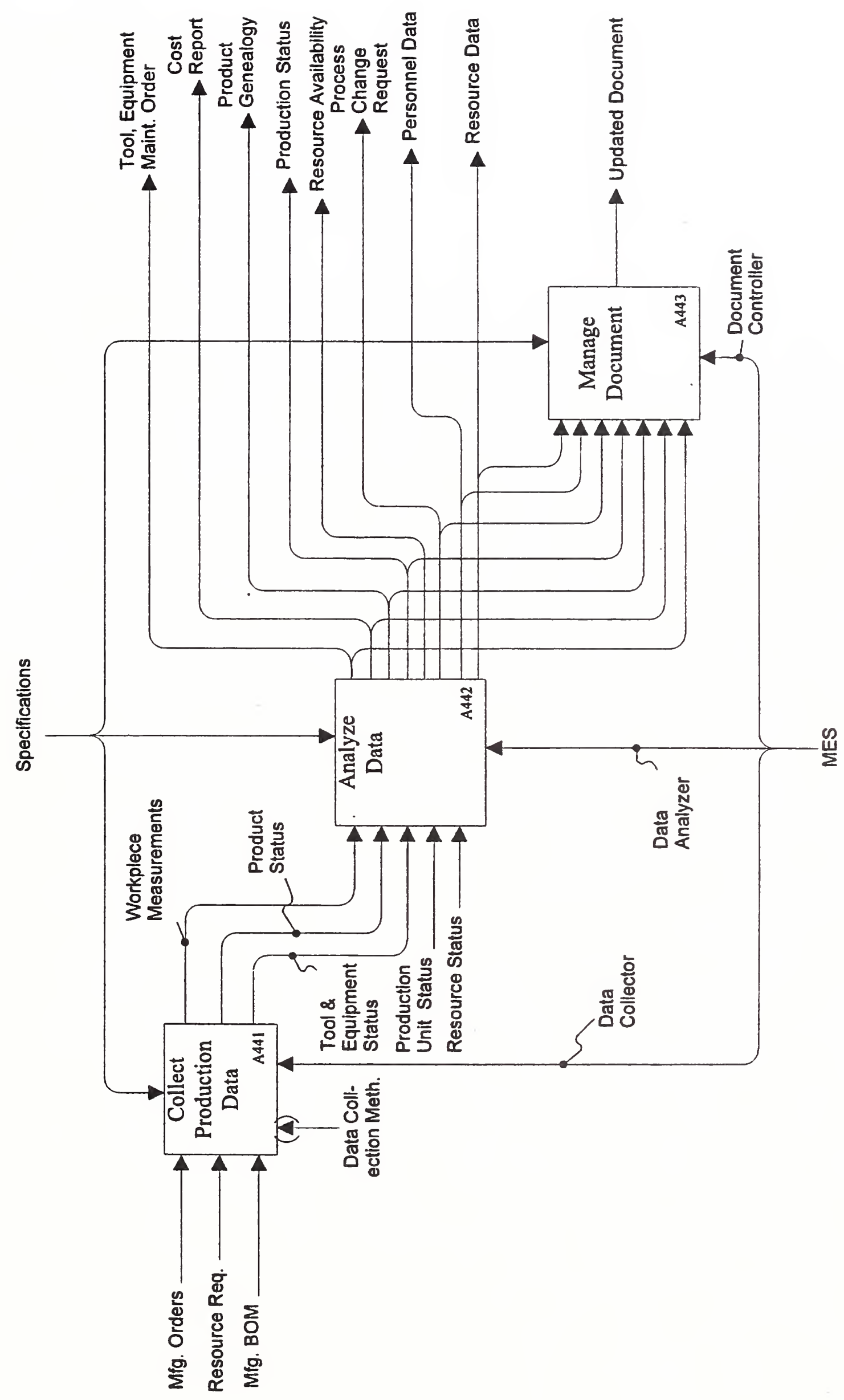

Activity A44 Manage Factory-floor 


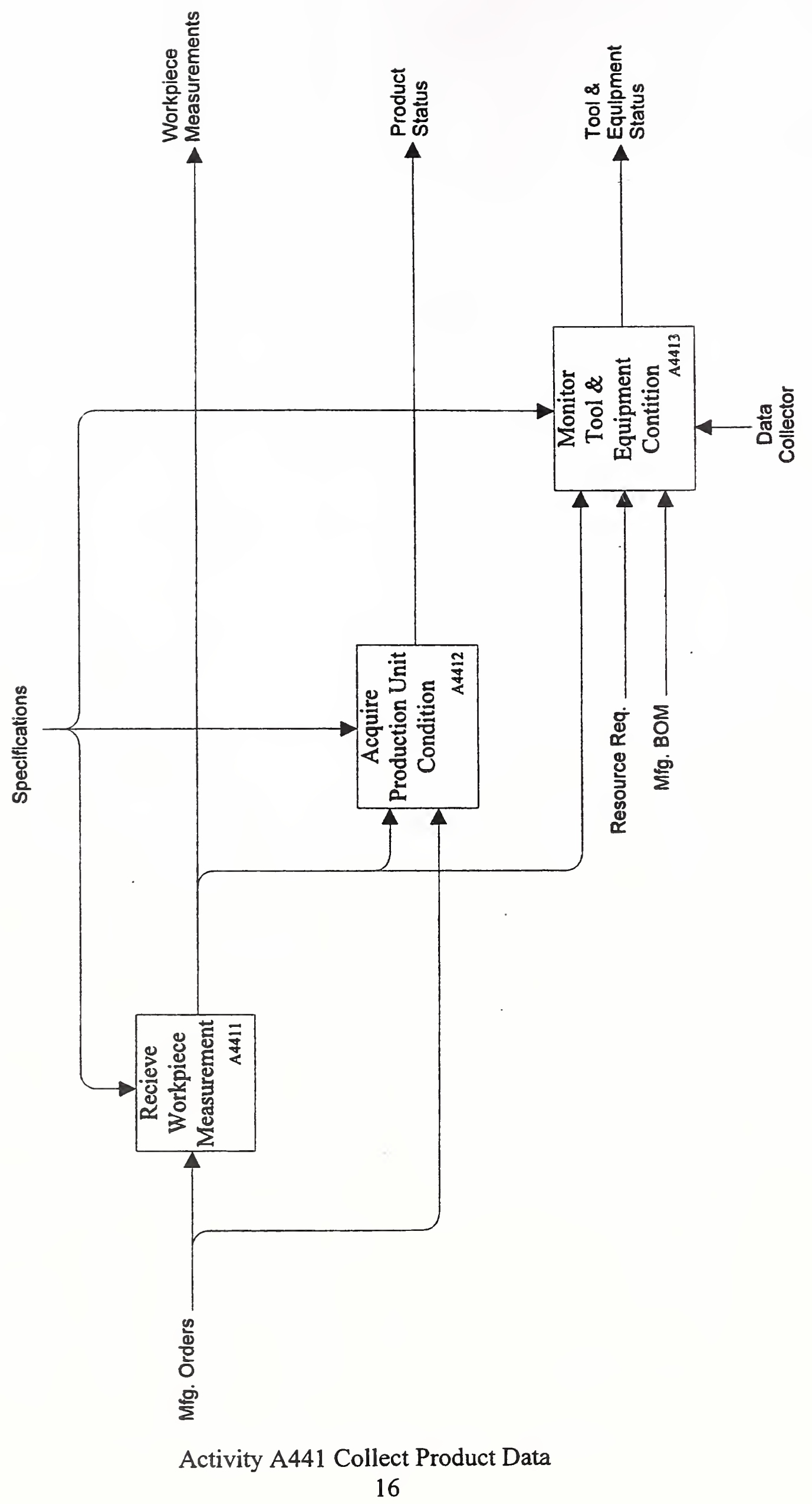




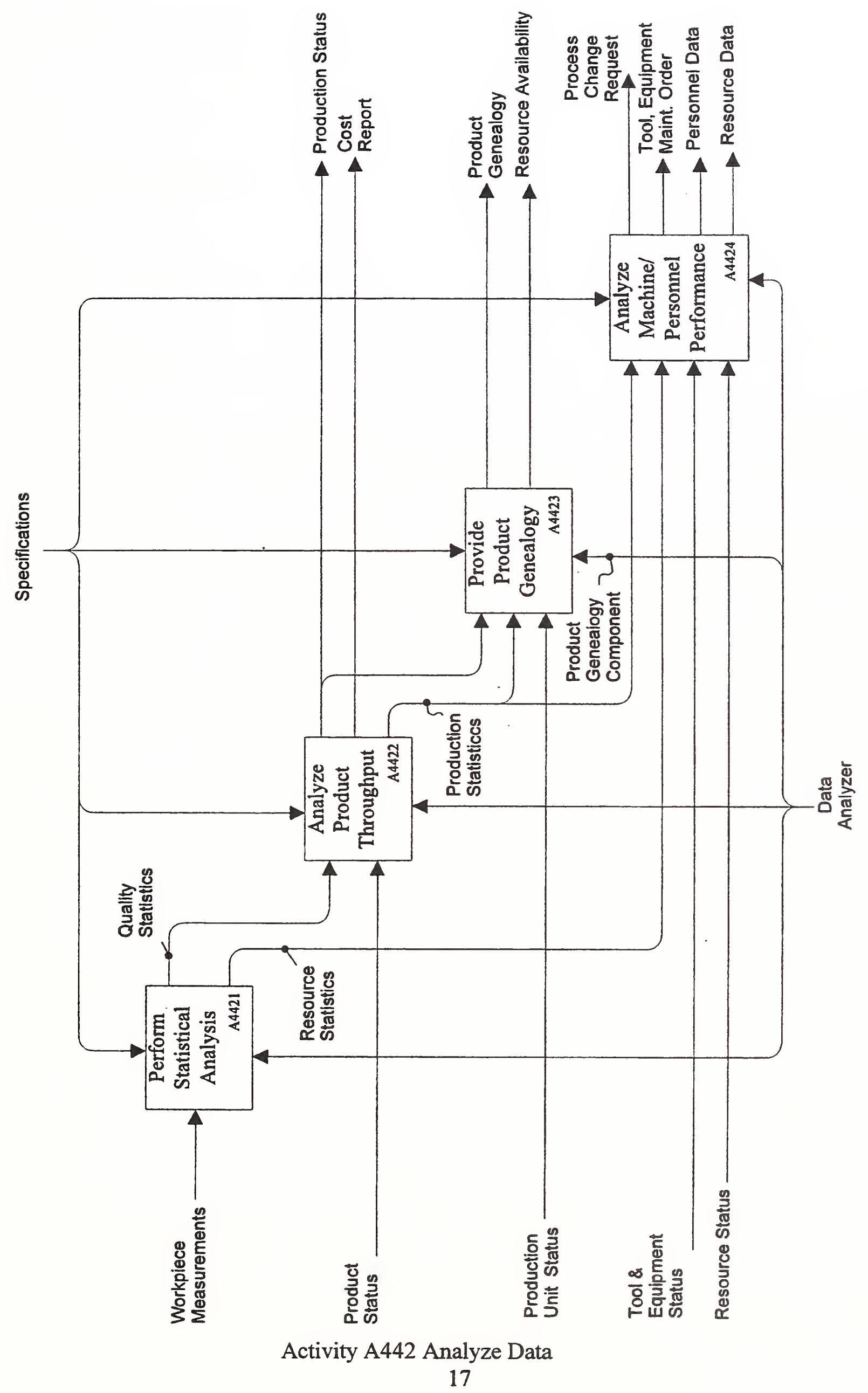




\section{A.2 Vocabulary}

Terminology (The following terms are used in activity and ICOM definitions.)

Batch: One or more lots are identified as one group that is treated by some processes as a unit. After the batch is treated, the batch can be dissolved, and individual lots are routed separately.

Job: A batch or lot that is scheduled to be released for production. (More detailed description is in [8]).

Lot/load: One or more parts/components in a group that travel through the production process as a unit. Lot and load are synonymous. A lot has a released date and time, a due date/time, and an actual finished date/time.

Production unit: In a manufacturing facility (factory or shop), a product unit can be a batch, lot, or a single part. Each production unit has a unique identification, maintained by the system.

Resources: Skills and physical entities that are required for performing production activities. Examples are stock materials, equipment (machining centers, automatically guided vehicle, robots, measuring machines, etc.), tools (fixtures, cutters, adapters, hand tools, gages, computer programs, tapes, etc.), labor skills, and energy.

\section{Activity Definitions:}

A1 - Engineer Product and Process:

Design products and generate a manufacturing process plan and alternative plans. The product design engineering includes functional requirements, conceptual design, embodiment design, detailed design, design analysis, and the specification of bill of material. The manufacturing process engineering includes process selection, operation planning, workpiece routing, and equipment/device control program generation. This activity provides design and processing information for the downstream resource planning and manufacturing execution.

A2 - Plan Enterprise Resources:

Analyze parts and perform make/buy decisions for all the parts. Develop business plan and schedule to acquire necessary resources and/or to produce products for the market. The enterprise resources include material, finished parts, equipment, and labor skills. The enterprise resource planning function includes financial and order management, production and material planning, master production scheduling, capacity requirement planning, and job definition. It also includes business process planning and resource requirement specification. 
A3 - Acquire Resources

Based on resource requirement plan, purchase resources from suppliers to meet the production schedule. This activity is supported by supply chain management, which includes distribution, logistics, transportation management, and advanced planning.

A4 - Execute Manufacturing Orders

Based on the production plan and master schedule, carry out manufacturing orders in a production facility to produce finished goods. This activity includes initiate, manage, and report on production activities.

A5 - Manage Sales and Services

Manage sales of products and services to customers, including product delivery and receipts, product configuration, customer orders, quotes to customers, product returns, and post-sale service.

A6 - Control Equipment and Process

Using pre-programmed instructions, control and monitor equipment motions and processes in real time. This activities usually involves distributed numerical control, programmable logic control, and factory-floor data collection.

A41 - Develop Operation Sequence \& Detailed Schedule

Based on the production plan and the master production schedule, define, sequence, and schedule operations locally on the levels of work cell, workstation, and machine in order to optimize productivity, such as minimize setup time, maximize throughput, minimize idle time, minimize queue time, and adjust shift pattern when new priority is in effect.

A42 - Dispatch Production Units

Determine which production unit in the queue is best processed next. The objective is to minimize the lead time and lateness.

A43 - Track Production Units and Resources

Provide the information on where any production unit is at all times and its disposition. Also provide the product genealogical information, such as who worked on it, current production information, component materials by supplier, lot number, serial number, any rework, measured data, or other exceptions related to the product. In the same time, provide the status information on specified resources, such as tools, devices, machines, and stock materials, at all times.

A44 - Manage Factory-floor Data/Document

Provide hardware/software interface links to obtain mission-critical data pertinent to production activities. Collect the data from the factory and analyze them for multiple purposes, such as product throughput, quality, delivery, and equipment maintenance. Manage documents, such as cost reports, maintenance orders, inventory reports, process change requests, manuals, specifications, company policies, etc. Control the data collection, access, and distribution. Provide versioning control of documents, such 
as part programs, operation instructions, manufacturing orders, detailed schedules, part drawings, engineering change notices, production unit records, records of communication from shift to shift, manuals, standards, company policies, safety regulations, etc.

\section{A411 - Develop Production Activity}

Sequence production operations based on priority, characteristics, setup changes/time, master production schedules, etc. Also, generate alternative operation sequences to recognize possible production changes, such as priority changes, machine downtime, etc.

\section{A412 - Define Production Unit}

Identify a lot or batch by decomposing or aggregating manufacturing orders. Each lot or batch is scheduled, processed, monitored, and tracked by the system as a unit.

\section{A413 - Schedule Production Unit}

Add start and finish time information to a lot or batch dictated by the operation sequences. The goal is to optimize productivity and quality and to conform to the master production schedule.

\section{A414 - Schedule Resource}

Add start and finish time information on each resource that is used by operation(s) in the production.

\section{A415 - Allocate Resource}

Assign and make resource available to operations that need the resource before they start. Equipment must be properly setup. This activity issues an assignment that associates a type of resource and quantity of it to specific operation(s) that need(s) the resource for a specific time period.

\section{A421 - Release Resources}

Based on resource allocation, release resource for the production activity in a timely manner. This activity results in physical materials, tools, etc., being moved from inventory or a storage to production cells or workstations.

A422 - Direct Personnel

Assign workers with adequate skills to perform specific operations according to the detailed schedule.

\section{A423 - Release Production Units}

Based on the detailed schedule, release production units to work cells or workstations and initiate processing the production units.

\section{A431 - Track Resources}

Follow up and monitor the status of resources. On-line track resource usability and consumption. Create a record of history of resources that are necessary to be traced. 
A432 - Monitor Personnel

Follow up personnel status and report the status. The report includes attendance, labor skill changes, job assignments, time performed on each assignment, and material/tool preparation time.

\section{A433 - Manage Process}

Monitor a production process and timely make decisions to adjust detailed schedule and process plan when unexpected situations occur. These activities should be coordinated with the process and equipment control functions. Process management includes alarm management to make sure factory person(s) are aware of process changes that are outside acceptable tolerances. It also includes process setup and tool preparation before production units are dispatched for processing. It maintains a history of past events or problems to aide in diagnosing problems.

\section{A434 - Manage Quality}

Provide timely analysis of measurements collected from products and processes to control product quality. Check the current production rate with the detailed production schedule. Identify problems in production requiring attention. Recommend proper actions to correct the problems. Make the statistics and status of products and processes visible to production/business management personnel.

A435 - Track Products

Monitor the progress of production and provide up-to-minute report on the production status, such as the quantity of a product made, scrap rate, rework rate, and the comparison to the production schedule.

\section{A441 - Collect Production Data}

Using data collection devices, acquire data by measuring and sampling workpieces, products, and production processes to support the management of product, quality, and process.

\section{A442 - Analyze Data}

Using collected data and adequate algorithms, analyze the data and generate record and reports, and make them available for decision making and product tracking.

\section{A443 - Manage Document}

Collect (or generate), maintain, and distribute production-related documents and records to support the production, factory-floor decision making, and product traceability.

\section{A4411 - Receive Workpiece Measurements}

Using factory-floor data collection devices, acquire and collect measurements on workpieces, labor records, process conditions to monitor the process performance and product quality. 
A4412 - Acquire Production Unit Condition

Using data collection mechanisms, such as bar code readers or manual input devices, acquire data on the production units to determine where they are and how many units of a product have been finished. Provide on-line, up-to-minute product status information. The data are made available and visible to production as well as business management.

\section{A4413 - Monitor Equipment Condition}

Using the data measured from product and process, indicate the status of tools, devices, and machines being used in production to determine whether they are still proper to function or need adjustment or maintenance.

\section{A4421 - Perform Statistical Analysis}

Conduct statistical analysis on data collected from the shop floor for tracking process performance and ensuring product quality.

\section{A4422 - Analyze Product Throughput}

Calculate the quantity of a product completed, check it against the schedule, and make it available to authorized personnel to view.

\section{A4423 - Provide Product Genealogy}

Create record on the product for traceability, including operations, process parameters, lot number, batch number, supplier, operator identifications, product measurements, and any exceptional processing conditions occurred. Make the record available to authorized personnel.

\section{A4424 - Analyze Machine/Personnel Performance}

Using the collected process data, analyze machine usage, production rate, capability, and estimate maintenance schedule. Also, analyze worker's performance, such as productivity, labor skill, and attendance record.

\section{Input, Control, Output, and Mechanism (ICOM) Data (information flow) Definitions:}

\section{Actual Production Steps:}

An actual production step is a detailed instruction to equipment or workers to execute production activity, such as load tools to a machine, start a milling cycle, drill a hole, check the actual dimension of a feature, etc.

\section{CAD/CAPP/CAM/PDM:}

The computer systems for product design and modeling (Computer Aided Design $\mathrm{CAD}$ ), engineering, process planning (Computer Aided Process Planning - CAPP), machining numerical control programming (Computer Aided Manufacturing - CAM), product data/process management (Product Data Management - PDM). A system includes interface, data repository, and data process software [11]. 
Controller:

Usually hybrid hardware/software systems. Examples are distributed control systems(DCS), programmable logic controllers(PLC), distributed numerical control(DNC), and supervisory control and data acquisition(SCADA) systems.

Cost Report:

A report on manufacturing cost of producing a part. It contains the costs of material, labor, usage of equipment, etc.

Data Analyzer:

A software component that provides up-to-minute report of actual manufacturing operations results along with the comparison to past history and business expectations. The results include such measurements as resource utilization, resource availability, product cycle time, conformance to schedule, and performance to standards.

Data Collection Methods:

The use of data collectors to obtain information on workpieces, timing, personnel, lots, and other critical entities for production management in a timely manner.

Data Collector:

A collection of devices with control software that are linked to factory-flow production equipment to gather data either manually or automatically from the manufacturing facility in an up-to-minute time frame.

Delivery Schedule:

The schedule of delivery of purchased resources.

Design Knowledge:

The information (rules, logic, or examples) which a human designer brings to bear on design problems, including design techniques and implementation techniques. Many different types of design knowledge are used in different design activities, such as decomposition knowledge, assignment knowledge, consolidation knowledge, and optimization knowledge.

Detailed Schedule:

A plan that specifies starting time and finished time of each production unit in the queue locally to an area in the manufacturing facility, such as a work cell, a workstation, or a machine.

Document Controller:

A mechanism, usually software, that controls records and forms that support product life-cycle activities, such as manuals, drawings, computer models, procedures, recipes, programs, engineering change orders (ECO), shift-to-shift communication records, etc. 


\section{ERP/MRPII:}

Enterprise Resource Planning (ERP) and Manufacturing Resource Planning (MRP) II are the systems that provide financial, order management, productions and materials planning and related functions. The Modern systems focus on global planning, business processes and execution across the whole enterprise (intra-enterprise systems), with an accrued recent importance of aspects like supply chain planning and the whole supply chain management aspects and extending to include the whole inter-enterprise supply chain.

Equipment Operation Instructions:

Specific operation steps or recipes that used to control machine movement, such as machining, welding, assembly, material movement, etc.

Labor Records:

A labor record is a piece of data that records the time, the attendance, tasks performed, tasks assigned, skill level, and certificates of a worker.

List of Purchased Resources:

A list of resources that are purchased from suppliers. For each resource item, the list contains resource number, description, purchased date, quantity, cost, and other relatedinformation that is company specific.

Machine Tools:

A machine tool is a machine with accessories that provides the capability of machining, such as milling, turning, drilling, and grinding.

Manufacturing Bill of Material (BOM):

A list of parts that are scheduled to be manufactured in the factory. For each part, the BOM contains part number, description, quantity, description, etc. Manufacturing $\mathrm{BOM}$ is the manufacturing version of product structure and part list in a corresponding production system, known as "as-built configuration", which support manufacturing engineers to consider additional information when planning how to manufacture the product, i.e., manufacturing capabilities, physically assembly possibilities, and the availability of parts [13].

Manufacturing Execution System (MES):

A production activity management system that initiates, guides, responds to, and reports on production activities on-line and in real time to production management people. The system aids the Execute Manufacturing Orders activity.

Manufacturing Knowledge:

The information (rules, logic, examples) that a manufacturing engineer brings to bear on manufacturing engineering problems, including production techniques and implementation techniques. Many different types of manufacturing knowledge are used in different manufacturing activities, such as decomposition knowledge, assignment 
knowledge, consolidation knowledge, and optimization knowledge which are used in process planning, resource planning, production planning, and scheduling.

Manufacturing Orders:

Instructions that are sent to factories to start jobs to fulfill customer orders. The starting dates are specified in the manufacturing order according to the production plan and the master production schedule.

Market/Customer Requirements:

A list of customer needs based on market studies, detailed evaluation of the competition, and review of all available literature. It includes the description on product performance, appearance, delivery time, target price, volume, safety, and environment [12].

Master Production Schedule:

A plan that specifies starting time and finishing time of each job in the job queue that are for producing products required by customers. The plan contains job IDs, starting dates, and due dates.

Operation Sequence:

A set of step-by-step instructions that specify how to perform tasks to process a workpiece in an local area, such as a machine, a workstation, a work cell.

Personnel Assignments:

A list of workers who are assigned to perform specific operations in the production plan. Each worker is assigned to perform or monitor one or more operations, usually, with due dates.

Personnel Data:

A record of personnel assigned to perform production activities. It provides work hours, on-station time, skills, certificates, etc.

Personnel Reassignments:

Requests to reassign workers to new tasks.

Personnel Tracking Component:

A software component in MES that aids users to track workers in a manufacturing facility.

Planning Policies:

Rules, regulations, strategies to plan business, engineering, and production activities.

Process Adjustments:

Requests from operators to process planners to modify the process plan or to adjust certain predefined parameters to improve process performance. 
Process Change Request:

Feedback from factory-floor production requesting changes to process plan when some problems in the process plan were found. Changes can be process parameter changes, tool changes, setup changes, etc.

Process Management Component:

A software component in MES that aids users to manage processes.

Process Performance:

Measures of how good parts, components, and products are produced by a process. Process performance include production rate, product quality, and process capability.

Process Plan:

A plan that specifies operation sequences, equipment, and process parameters for manufacturing a product.

Process Status:

A report of the conditions of a process being monitored. The report includes alarms, process changes or shifts, workpiece throughput, etc.

Product Bill of Material (BOM):

An index to illustrate the structure and detailed information of product, component and part, known as "as-designed configuration" or "Engineering BOM- EBOM". It includes the item number of letter, the part number, the quantity needed in the assembly, the name or description of the component, the material from which the component is made, and the source of the component [12].

Product Delivery:

Move finished products to customers who requested the products.

Product/Process Statistics:

Measurements and statistical analyses of process performance and quantities and the quality of products.

Product Genealogy Component:

One of the components in MES system, which provides the visibility to where work is at all times and its disposition. Product genealogy information may include who worked on the product, components materials by supplier, lot, serial number, current production conditions, and any alarms, rework, or other exceptions related to the product. This information provides traceability of each part and component.

Product Inventory:

The inventory information on a product. The information is updated when finished products are sent to storage. 
Product Order:

Quantities of parts or products to be produced, usually with nominal delivery dates, as specified by enterprise sources external to the manufacturing facility.

Product Status:

Current conditions of a product, including the quantity of the product made, check it against the schedule, measurement and test results, and any exceptional process conditions occurred.

Product Tracking Component:

A software component in MES that aids users to track resources used in a manufacturing facility.

Production Activity Planning Component:

A software component in MES that aids users to plan production activities.

Production Orders:

Instructions that are sent to a local area of a factory to start processing a production unit with the starting date and time and the ending date and time.

Production Statistics:

Measurements and statistical analyses of the production process and the quantity and quality of products being produced.

Production Status:

A report on the state of all scheduled operations and production units. This also includes the information on resources, process setup, job schedule, and material routing.

Production Unit Definition:

Definition of a lot or a batch. It includes an ID, number of workpieces, and the descriptions of the workpieces. Each workpiece may have a serial number. In the product record, workpiece ID and production unit ID are associated.

Production Unit Routing:

A plan that specifies the traveling route of a production unit in a manufacturing facility. The plan also specifies stops for processing and queuing.

Production Unit Scheduling Component:

A software component in MES that aids users to schedule production unit to be processed locally in a manufacturing facility. 
Production Unit Status:

A snapshot of a product unit being processed. The status includes the quantity of finished product, scrap rate, rework rate, product measurements analyses, and a check of the status with the master production schedule.

Purchase Orders:

A purchase order is an instruction to buy certain resources (material, parts, components, tools, machines, etc.) from a supplier.

Quality Statistics:

The statistical data pertinent to the quality of the product measured in-process or postprocess based on the design specifications [11].

Released Units:

Production units that are released for processing in the manufacturing facility.

Resource Availability:

A report on whether needed resources are available for production during specified time periods.

Resource Data:

The data that indicate the condition of a resource based on inspection or measurement analysis.

Resource Records:

A resource record is a piece of information that indicates where the resource is located and who is using it for which operations on which production unit for how long. If it is a piece of equipment, the record should also show whether it is functional.

Resource Release Orders:

A resource release order is an instruction that requests to release resources from storage or from current user to a new user.

Resource Requirements:

A list of resources required to support production jobs.

Resource Statistics:

The statistical data pertinent to the state of resources inspected or measured in-process or post-process.

Resource Schedule:

A plan of control resource availability and allocation. It specifies a group of resources that each resource is assigned to which operation or transferred from one place to another in a specific time period. Only resources that are used/shared by multiple work cells or workstations are on the resource schedule. 
Resource Scheduling Component:

A software component in MES that aids users to schedule the release of resources to work cells, workstations, and/or machines.

Resource Status:

A snapshot of a resource used in production. The conditions, location, and service time of the resource are reported. If it needs maintenance, replacement, or disposition, the resource is marked accordingly.

Resource Tracking Component:

A software component in MES that aids users to track resources being used in a manufacturing facility.

Service Delivery:

The delivery of post sale service to customers.

Specifications:

Sets of description of standard engineering, manufacturing, and business practices that guide and control the product development process.

Statistical Quality Control (SQC):

SQC is a software component in MES that aids users to analyze and control product quality and to monitor process capability and shift.

Sale and Service Management (SSM):

A mechanism that supports sales force automation, product configurations, service quoting, product returns, and post-sale service.

Standard Part Library:

An information library or database that contains standard parts. A standard part is a member of a class of parts that has a generic function and is manufactured routinely without reference to its use in any particular product. Examples of standard parts are screws, bolts, rivets, jar tops, buttons, most beams, gears, springs, and washers.

Supply Chain Management (SCM):

SCM is a mechanism that aids users to manage the supply of resources, including forecasting, distribution and logistics, transportation management, electronic commerce, and advanced planning.

Task Assignments:

Records of assigning tasks with due dates to workers.

Tool, Equipment Maintenance Order:

An instruction indicating specific tools, machines, or devices that need maintenance before performing any production activities. 
Tool and Equipment Status:

The condition of all tools and equipment. Condition includes the usage load, wear and tear, broken status, and the forecasted life span.

Tool Usage Instructions:

Instructions that guide users to properly use tools in production.

Tooling Design:

Specification of the form, function, and material of a tool (e.g., cutter, fixture, and probe). There are two major subtype of tooling design: (1) tool assembly design that specifies the assembly of a tool or fixture from standard components, and (2) special tool design which must be fabricated.

Updated Document:

Document that is modified to include new information.

Workpiece Measurements:

The assessment and comparison of workpiece geometry, dimension, tolerance, and functions for the conformance to the design attributes. 


\section{Appendix B. Interface Definitions}

// Interface Definitions for Manufacturing Execution and Process

// Planning Objects

/I

// Language: CORBA Interface Definition Language (IDL)

/I

// Date of creation: August 20, 1997

// This work is sponsored by the ATP TIMA Focused Program

module Manufacturing_Execution

/*

This module defines interfaces for manufacturing execution

software objects.

*/

\{

typedef string Identification;

typedef string Name;

typedef string Description;

enum Workpiece_status \{unfinished, finished, scraped\};

enum Factory_hiearchy $\{$ factory, shop, workstation, cell, machine_tool\};

enum Part_status \{ready, in_order, unknown\};

struct Time

\{

double second;

short minute;

\};

short hour;

struct Date

\{

short day;

short month;

\}

long year;

struct Date_and_time

\{

Date the date;

Time the time;

3 
struct Measured_value

/*

A measured value is the measurement result which consists of a number and a unit, such as $1.23 \mathrm{~cm}$.

*/

\{

double measure; // the number component, such as 1.23

string unit; // the unit componet, such as $\mathrm{cm}$

\}

struct Organization

/*

An organization is where a job is performed, i.e., company, division, factory, shop, work cell, workstation, etc.

$* /$

\{

string organization_name; // the name of the organization

string address; // the location of the organization

\}

struct Job_status

/*

Job status reflects current condition of a job, which indicates

when the job is dispatched, how much has been finished, and the estimated finished time.

*/

\{

Date_and_time dispatched_time;

float percent_finished;

\}

Date_and_time estimated_finished_time;

struct Equipment

/*

A system that is used for producing products. Equipment includes machines and tools.

*/

\{

Name equipment_name;

string type;

string maker;

string equipment_status;

\} 
struct Machine

/*

A powered system that is used in producing products, such as machining tools and centers, robots, assembly machines, and measuring machines.

$* /$

\{

Identification machine_id;

string maker;

string model;

string usage; // information about the use of the machine

string machine_status;

\}

struct Tool

/*

A handheld device that is used in producing products in factories,

*/ such as cutter, holder, adapter, gage, mold, die, etc.

Identification tool_id;

string maker;

string model;

Measured_value size;

string status;

string usage; // information about the use of the tool

Description location;

\}

struct Fixture

/*

A device that is used to hold workpiece(s) in a fixed position and orientation on a machine.

*/

\{

Identification fixture_id;

Description functions;

string maker;

string status;

Description location;

\}

struct Document

/*

A collection of related inforamtion to describe resources or procedures related to activities in production. 
Name document_name;

string document_type;

Date_and_time check_in;

Date_and_time check_out;

Description location; // the place where is document is placed.

Name contact; // the person who is responsible for the document.

\}

typedef sequence $<$ Tool $>$ Tools;

struct Job_order

/*

A job is a sequence of operations to convert workpieces to finished parts. An order that assigns resources to a job and starts it in

$* /$

a factory.

\{

Identification job_order_id;

string job_order_type;

Description job_order_description;

Date_and_time dispatched_date_and_time;

Date_and_time completed_date_and_time;

string approval_level;

\}

struct Work_setup

/*

Work setup consists of instructions on setting up workpieces on a machine table.

*/

\{

string setup_instruction;

\}

string alternat_setup_instruction;

struct Workpiece

/*

A piece of material in process to be converted from stock to final part.

*/

Identification workpiece_id;

Workpiece_status status;

Factory_hiearchy workpiece_location; 


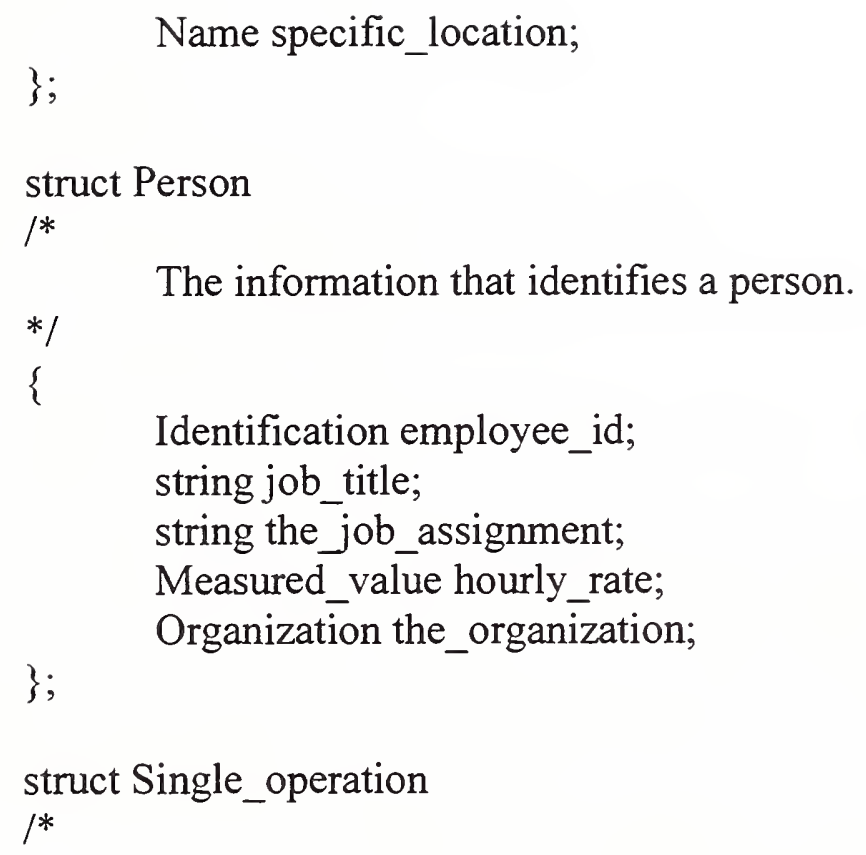


void develop_job_order(inout Job_order a_job_order);

\} void approve_the_order(inout Job_order a_job_order);

interface WorkSetupPlanning

/*

An activity of developed work setup instructions.

*1

\{

void create_primary_setup_insturctuions (out Work_setup setup);

\}

void create_alternate_setup_instructions(in Work_setup setup);

interface EquipmentTracking

/*

An activity of tracing a piece of machinery or a

$* /$ tool that is used in processing workpiece.

\{

attribute Equipment a_piece_of_equipment;

void track_equipment();

void report_status(out string status);

\}

interface MachineTracking

/*

An activity of tracing a machine to determine its production status, maintenance schedule, and availability.

$* /$

\{

attribute Machine a_machine;

void track_machine (out string machine_status);

\}

void report_machine_usage(out string machine_usage_report);

interface ToolTracking

/*

An activity of tracing a tool to determine its availability, maintenance schedule, tool life, and location.

*/

attribute Tool a_tool;

attribute string location; 
void track_tool(inout string tool_status);

void report_status(out string status, out string tool_location);

\}

interface FixtureTracking

/*

An activity of tracing a fixture to determine its availability, maintenance schedule, and location.

*/

attribute Fixture a_fixture;

void describe_function(inout Description funtions);

void report_stuats (inout Description location,

\} inout Description status);

interface WorkpieceTracking

/*

An activity of tracing a workpiece to determine its status.

*/

\{

void allocate(inout Workpiece a_workpiece);

void workpiece_progress(inout Workpiece_status status);

void workpiece_location_trace(out string the_location);

\} void release(inout Workpiece a_workpiece);

interface OperationPlanning

/*

An activity of developing a sequence of operatioins in manufacturing.

*/

\{

attribute Operation_group a_group_of_operations;

\}

void develop_operations ();

interface PartInformation

/*

The information that identifies a particular part.

*/

attribute string part_id;

attribute string part_name;

attribute Description part_description; 
attribute string design; // CAD file name and location attribute Measured_value manufacturing_cost; // estimated cost attribute long total_number;

\} attribute Part_status status;

interface PartStatusReport

/*

An activity to state the current status of a part, such as how many have been produced, when is the due date, estimated finished date, etc.

*/

attribute PartInformation a _ part;

void report_status(inout Part_status status, out string part_id, out string name);

\}

interface PartOrder

$/ *$

The customer order of a part.

*/

attribute Identification order_id;

attribute string type;

attribute PartInformation ordered part;

attribute Description order_description;

attribute Date and time submitted date;

attribute Date_and_time delivery_date;

attribute Measured_value part_quantity;

attribute Measured_value price;

void report_part_order();

\}

interface JobAssignment

/*

An activity of assigning a specific job to a person.

$*$

\{

void assign_job(inout Person a_worker);

void modify_hourly_rate(inout Person a_worker);

\} 
interface DocumentControl

/*

An activity of managing documents related to product and manufacturing.

$* 1$

\{

attribute Document the_document;

void check_in();

void check_out();

\}

void update_document_information();

\}; //end module Manufacturing_Execution

module Process_Planning

/*

Process Planning interfaces

*/

\{

struct Relative_orientation

/*

An orientation, consisting of three theorectically orthogonal vectors

*/ indicating a reference frame, relative to machine coordinates.

\{

double ux, uy, uz; //directional vector in the $\mathrm{x}$-direction of the machine table double vx, vy, vz; //directional vector in the y-direction of the machine table double wx, wy, wz; //directional vector in the z-direction of the machine table

\}

struct Relative_position

/*

The position of an object relative to machine coordinates.

*1

\{

\}

double $\mathrm{x}, \mathrm{y}, \mathrm{z}$; //relative to the machine table coordinates

struct Properties

/*

*/

A specific characterization of an object.

string property_name; 


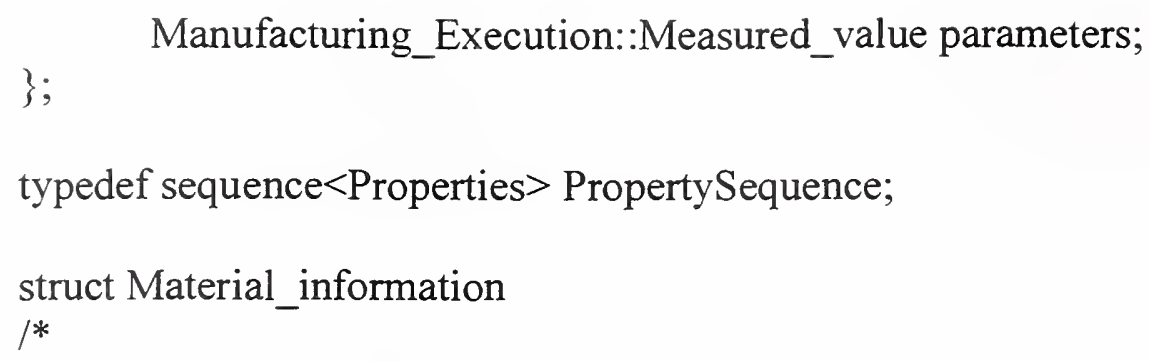


string file_location; //file directory and file name string file_type; $\quad / \mathbb{N C}$, robot, tool path, etc.

\}

string machine_controller_description; //controller name, model, etc.

interface MaterialSelection

/*

An activity of selecting stock material.

*1

\{

attribute Cad_data cad_file; attribute Material_information selected_material;

void select_material(in Cad_data cad_model, out Material_information mi);

\}

interface ManufacturingFeatureDerivation

/*

An activity of recognizing and defining portions of stock material

*/ or workpiece that need to be processed.

\{

attribute Cad_data part_model;

attribute Cad_data manufacturing_features;

\}

void derive_manufacturing_feature(in Cad_data pm, out Cad_data mfs);

interface ManufacturingResourceSelection

/*

An activity of identifying machines, tools, and materials to be

$* /$ used in manufacturing processes.

\{

attribute Cad_data manufacturing_features;

attribute Cad_data part_model;

attribute Material_information material;

attribute Manufacturing_Execution::Equipment manufacturing_equipment;

void select_manufacturing_resources(in Cad_data $\mathrm{mf}$,

in Cad_data pm,

inout Material_information material_stock,

\} out Manufacturing_Execution::Equipment eqp); 
interface OperationSelection

$/ *$

Identifying operations that are used in transforming material stocks

to products.

*/

attribute Manufacturing_Execution::Equipment manufacturing_equipment; attribute Cad_data part_model;

attribute Cad_data manufacturing_features;

attribute Material_information material_stock;

attribute Manufacturing_Execution::OperationSequence manufacturing_operations;

void generate_operation(inout Manufacturing_Execution::Equipment $\mathrm{mr}$, inout Cad_data pm, inout Cad_data mf, inout Material_information stock,

\} inout Manufacturing_Execution::OperationSequence mops);

interface SetupSpecification

/*

An activity of describing workpiece setup on the machine based on work setup instructions.

$* /$

\{

attribute Manufacturing_Execution::OperationSequence manufacturing_operations; attribute Cad_data part_model;

attribute Cad_data manufacturing_features;

attribute Setup part_setup;

attribute Setup fixture_setup;

void specify_setups(in Manufacturing_Execution::OperationSequence manufacturing_operations, in Cad_data

\} part_model, in Cad_data mfs, out Setup part_setup, out Setup fixture_setup);

interface OperationSequencing

/*

An activity of ordering operations to make an operation list.

attribute Manufacturing_Execution::OperationSequence manufacturing_operation_sequence;

attribute Manufacturing_Execution::OperationSequence

alternative_manufacturing_operation_sequences;

void sequence_specification(in Manufacturing_Execution::OperationSequence 


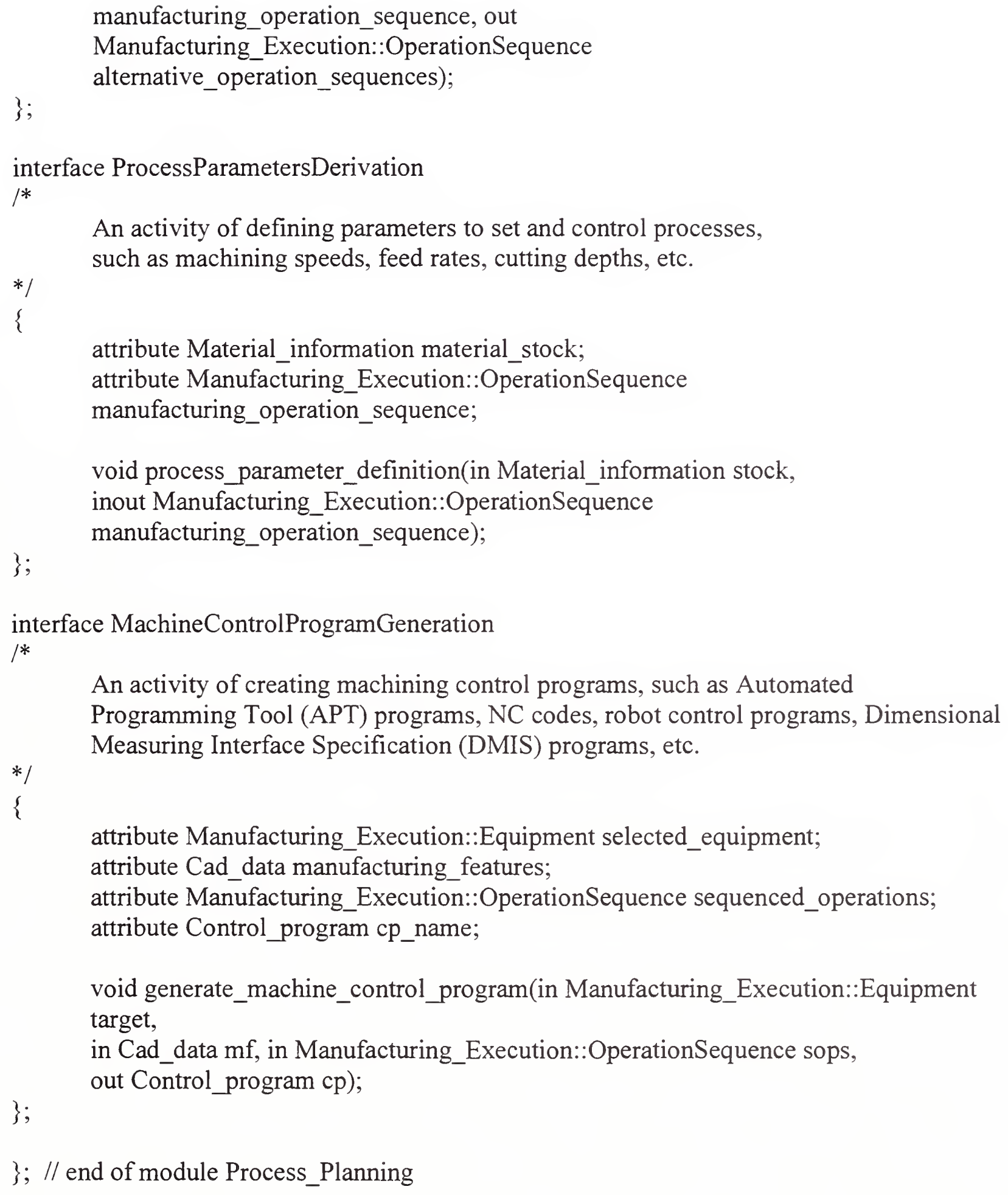

\}; // end of module Process_Planning 


